\title{
A PRESENÇA DA FFCL NA IMPRENSA RIO-PRETENSE: ANÁLISE DOS TÍTULOS DAS MATÉRIAS JORNALÍSTICAS
}

\author{
Marcela Lopes Gomes ${ }^{1}$ \\ União das Escolas do Grupo FAIMI de Educação, FAIMI
}

\section{RESUMO}

A Faculdade de Filosofia, Ciências e Letras de São José do Rio Preto constituiu-se como uma das primeiras FFCLs do interior paulista a ser mantida pelo governo estadual (Lei $\mathrm{n}$. 5.177, de 13 de janeiro de 1959). A criação da FFCL foi um projeto almejado por setores da sociedade rio-pretense, fruto do empenho de políticos, autoridades administrativas e profissionais liberais. O objetivo deste trabalho consiste em discutir a relação estabelecida entre a FFCL e segmentos da sociedade rio-pretense, a partir da análise dos títulos das matérias jornalísticas a respeito da faculdade, publicadas nos jornais locais no período de 1955 a 1965. Os primeiros resultados indicam que se inicialmente setores da sociedade riopretense ansiaram pela criação da FFCL, lutaram na campanha para sua estadualização e comemoram as primeiras conquistas da faculdade; gradativamente houve uma mudança no tom da imprensa local com relação à FFCL, um distanciamento gerado entre a faculdade $\mathrm{e}$ a sociedade local, o que culminou em uma crise que se expressou no período do golpe militar. Assim sendo, observa-se a repercussão do conflito de vozes sociais acerca da FFCL expressa nas páginas dos jornais. As publicações jornalísticas fornecem, pois, elementos para a análise das preocupações das classes e dos grupos dominantes de Rio Preto acerca da FFCL.

Palavras-chave: Ensino Superior - Brasil. Imprensa - São José do Rio Preto.

\section{THE PRESENCE OF THE FFCL IN THE PRESS OF SÃO JOSÉ DO RIO PRETO: ANALYSIS OF NEWSPAPER HEADLINES}

\begin{abstract}
The "Faculdade de Filosofia, Ciências e Letras", in São José do Rio Preto is one of first academic divisions in the interior of São Paulo to be supported by state government (Law n. 5.177, January, 13, 1959). The creation of the FFCL was a project sought by some local sectors, and it was a result of some political efforts, administrative authorities and some liberal professionals as well. The aim of this research is to discuss the relationship between FFCL and some segments of local society, by analyzing headlines published in local newspapers from 1955 to 1965 . The preliminary results show that if, firstly, some parts of city's society really sought-out the foundation of FFCL, they joined the campaign in order to make it part of the state education system and also celebrated the college's first few accomplishments. There then was a gradual change on the local press's viewpoint on FFCL and a detachment between the college and local society, which resulted in a crisis, made evident during the Brazilian dictatorship. Per consequence, one can see a constant conflict of ideas among the publications about FFCL through the local press. Print publications somehow provide elements to analyze the worries of both local classes and the dominant local groups regarding FFCL.

Keywords: Higher Education - Brazil. Press - São José do Rio Preto-SP.
\end{abstract}




\section{Apresentação}

A 448 quilômetros de São Paulo, encontra-se São José do Rio Preto, maior cidade da região noroeste paulista, com aproximadamente 406.220 habitantes, segundo dados parciais do censo 2010. A ocupação das terras que deram origem ao município de São José do Rio Preto ocorreu a partir de 1840, por pessoas oriundas do estado de Minas Gerais. Em 1852, Luiz Antônio da Silveira doou parte de suas terras para que o patrimônio originasse uma cidade. João Bernardino de Seixas Ribeiro liderou os moradores da vizinhança para a construção de uma pequena capela e um cruzeiro de madeira, em 19 de março daquele ano, considerado o dia da fundação da cidade. A emancipação política de São José do Rio Preto sucedeu-se por meio da lei n. 294, de 19 de julho de 1894, que transformou a cidade em um município cujo extenso território era limitado pelos rios Paraná, Grande, Tietê e Turvo, com mais de 26 mil km de superfície (atualmente o município possui uma área de 431,30 $\mathrm{km})^{2}$.

Dentro do espaço regional que envolve atualmente 96 municípios, a cidade exerce sua força e influência socioeconômica desde sua fundação. Assim, quando os trilhos da Estrada de Ferro Araraquarense (EFA) alcançaram a cidade em 1912, São José do Rio Preto passou a assumir, em definitivo, a condição de polo comercial de mercadorias produzidas no denominado "Sertão de Avanhandava" e de difusão de materiais provenientes da capital paulista.

Segundo dados do IBGE, indicados no Anuário Estatístico do Brasil, a população da cidade, na década de 1950, era de 65.852 habitantes, dentre os quais $61 \%$ residiam na área urbana. A produção econômica de Rio Preto manifestava uma forte atividade algodoeira e pecuária bovina, porém a principal atividade econômica da cidade era a comercial, contabilizando 63 empresas atacadistas e 858 varejistas. Além disso, contava com 76 estabelecimentos industriais que empregavam quase 1.200 operários, sendo que, em 1956, a produção das indústrias alimentícias do município correspondia a $2 / 3$ do valor da produção industrial de toda a sua região. Nessa década, a cidade experimentou diversas transformações, visto que passou por um progressivo êxodo rural e uma diversificação econômica que ocorreu no setor terciário, na industrialização e no desenvolvimento de atividades rurais subordinadas às necessidades industriais. Tais circunstâncias demandaram uma ampliação dos setores de transporte, comunicações, finanças e educação.

Esses dados do IBGE demonstram que a cidade de São José do Rio Preto passava, na década de 1950, pelas transformações econômicas e sociais que geraram uma ampliação da demanda pelo ensino superior no país. Nesse sentido, estavam postas as condições para se efetivar a aspiração de se instalar uma instituição de ensino superior na cidade. Dessa forma, em 1955, fundou-se a Faculdade de Filosofia, Ciências e Letras de São José do Rio Preto $^{3}$ a partir da Lei n. 394, aprovada em 26 de maio, e do Decreto n. 249, de 25 de agosto do referido ano.

Para compreender o contexto que envolveu a criação da FAFI, é necessário entender que a expansão do ensino superior no interior paulista está relacionada com o desenvolvimento das relações capitalistas, a partir da década de 1950. De acordo com Cunha (1989), nesse período ocorreu a intensificação do processo de industrialização e monopolização da economia. Um dos resultados dessas modificações na economia consistiu na mudança do modelo de ascensão das camadas médias para as hierarquias ocupacionais:

No interior desse processo, as camadas médias passaram a definir seu projeto de ascensão social como dependente do projeto de carreira dos 
jovens, a ser realizado mediante a obtenção de diplomas de curso profissional em escola superior, que propiciassem o desempenho de ocupações para as quais eles eram requisitos necessários. (CUNHA, 1989, p. 63).

Além disso, para Cunha (1989), outros fatores interferiram na ampliação da demanda por educação escolar, de modo a intensificá-la, quais sejam: o êxodo rural e o consequente aumento da população urbana, a redefinição do papel da mulher como trabalhadora na esfera extradoméstica, a elevação dos requisitos educacionais necessários ao preenchimento dos cargos nas burocracias públicas e privadas. Diante de tal panorama, intensificou-se a procura de jovens dos novos setores dominantes pelo ensino superior, bem como se ampliou a demanda por esse nível de ensino pelas classes médias, o que gerou um maior crescimento do ensino superior nesse período. O município de São José do Rio Preto também passou por essas transformações, como os dados anteriores indicam, o que engendrou as condições que propiciaram a criação da FAFI.

Este artigo objetiva, pois, acompanhar como se desenvolveu a relação entre a FFCL e setores da sociedade rio-pretense, a partir do conflito das vozes sociais que se expressaram nas páginas dos jornais locais, especificamente nos títulos das matérias jornalísticas de 1955 a 1965, ou seja, desde a criação da faculdade até os dois anos iniciais da ditadura militar ${ }^{4}$. Não obstante ao caráter sintético dos títulos, julgo que eles propiciarão a descoberta de fortes indícios desse conflito de vozes sociais, além de ser uma forma objetiva de se abranger as 487 matérias sobre a FAFI, publicadas no decorrer desse período de 10 anos.

Para tanto, os jornais selecionados como fontes de pesquisa consistem naqueles que apresentavam circulação permanente na década de 1950 (GOMES, 1975), a saber:

- A Notícia, fundado em 1924 por Nelson de Veiga e Dário de Jesus;

- A Tribuna, criado em 1949 por Coutinho Cavalcanti, Marcelino Cavalieri Jr. e Walter Camarero;

- Diário da Região, fundado em 1950 por Eufli Jalles;

- Correio da Araraquarense, criado em 1955 por Antenor Pousa Godinho.

Esclareço que o levantamento prévio das publicações sobre a FAFI nos referidos jornais foi realizado na Hemeroteca Municipal Professor Dário de Jesus, atualmente situada no Arquivo Público Municipal, para o projeto Preservação de Fontes da Educação Brasileira: a estruturação do arquivo histórico da FAFI - São José do Rio Preto, desenvolvido no ano de 2003.

A eleição da imprensa como fonte e objeto de pesquisa, deve-se ao fato de ela ser produtora e difusora de discursos a respeito de fatos, opiniões e acontecimentos, divulgando e consolidando representações sociais acerca da realidade, formuladas em determinadas condições históricas. Como analisa Bastos (2002, p. 152), “a imprensa cria um espaço público através do seu discurso - social e simbólico - agindo como mediador cultural e ideológico entre o público e privado, fixa sentidos, organiza relações e disciplina conflitos".

\section{A FFCL e a Imprensa Rio-Pretense}

O percurso de criação de uma Faculdade de Filosofia na cidade de São José do Rio Preto ocorreu da seguinte forma: em 1955, o vereador Daud Jorge Simão apresentou o projeto de lei n. 30, que propunha a criação da Universidade Municipal de São José do Rio 
Preto, aprovado pela Câmara Municipal em 24 de maio. Em seguida, o prefeito Philadelpho Gouveia Neto assinou a Lei n. 394/55, sancionando o texto aprovado pelos vereadores. Assim, por meio do Decreto n. 249/55, fundou-se o que se pretendia ser a primeira unidade da Universidade Municipal - a Faculdade de Filosofia, Ciências e Letras de São José do Rio Preto. Contudo, o empenho pela fundação de uma FFCL em solo local já se evidenciara em 17 de julho de 1953, quando houve uma tentativa de criação de uma FFCL vinculada à USP em São José do Rio Preto via Projeto de Lei n. 834, vetado pelo governador em 25 de julho de 1955.

Os jornais locais acompanharam, inicialmente, de maneira tímida esse processo, visto que nos dois primeiros anos após a criação da faculdade houve a publicação de apenas quatro matérias a respeito da FFCL, sendo duas notícias e dois artigos jornalísticos. Os títulos dessas notícias indicam que elas se limitavam a dar ciência aos leitores do processo de fundação da FAFI:

O projeto que visa criar a Universidade Municipal (A NOTÍCIA, 30 abr. 1955, p. 4).

Vai funcionar a Faculdade de Filosofia (A NOTÍCIA, 12 set. 1956, p. 1).

Já os artigos expressaram a exposição de pontos de vista sobre o processo de fundação da FFCL, porém ambos não foram assinados, fato esse recorrente em grande parte dos textos com responsabilidade jornalística publicados nos jornais rio-pretenses no período analisado:

A burocracia continua dificultando a vinda da Faculdade de Filosofia (A NOTÍCIA, 18 out. 1956, p. 1).

Órgãos técnicos do Ensino Superior manifestam-se contra a criação da Faculdade de Filosofia de Rio Preto (A NOTÍCIA, 15 set. 1956, p. 1).

Após a fundação da FFCL de São José do Rio Preto, o professor Raphael Grisi, diretor geral do Departamento de Educação do Estado de São Paulo, ex-secretário de Educação do Estado do Espírito Santo e livre-docente da FFCL da USP, foi nomeado diretor da faculdade municipal em dezembro de 1955, participando, desde o início, de sua instalação e organização. Os primeiros cursos que funcionaram na FAFI foram os de Letras Anglo-Germânicas, Letras Neolatinas, Pedagogia e História Natural.

A imprensa rio-pretense passou a apresentar um efetivo interesse em noticiar o desenvolvimento das atividades da FFCL somente a partir de 1957, ano do início do funcionamento da faculdade, ou seja, dois anos após sua criação. Aliás, esse constituiu o ano em que os jornais rio-pretenses destinaram maior espaço e atenção à FAFI, foram publicadas 163 matérias sobre a faculdade, com uma grande predominância de notícias jornalísticas. Nos primeiros meses de 1957, tais matérias relacionavam-se ao empenho da sociedade local pela autorização de seu funcionamento junto ao governo estadual, o que se evidencia nos seguintes títulos das notícias:

Periga o funcionamento da Faculdade de Filosofia em 57 (CORREIO DA ARARAQUARENSE, 02 fev. 1957, p. 1).

Por uma escola superior: De pé a mocidade riopretense no movimento em prol da Faculdade de Filosofia (A TRIBUNA, 05 fev. 1957, p. 6).

Rio Preto e a Alta Araraquarense querem o funcionamento, ainda este ano, da Faculdade de Filosofia Municipal (A NOTÍCIA, 05 fev. 1957, p. $1)$. 
Monumental o comício realizado em prol da Faculdade de Filosofia para São José do Rio Preto (A TRIBUNA, 09 fev. 1957, p. 6).

Ainda o funcionamento de nossa Faculdade de Filosofia. (DIÁRIO DA REGIÃO, 12 fev. 1957, p. 1).

Nesse período, houve a publicação de artigos de opinião que versavam também a respeito dos protestos estudantis em favor do funcionamento da faculdade:

Funcionamento da Faculdade de Filosofia: Os estudantes riopretenses irão à praça pública (DIÁRIO DA REGIÃO, 02 fev. 1957, p. 1). Os estudantes irão realizar comícios públicos de protesto (CORREIO DA ARARAQUARENSE, 02 fev. 1957, p. 6).

Além das manifestações públicas dos estudantes, os jornais noticiaram a adesão de um sindicato e de uma associação comercial no movimento a favor da FFCL, apoio esse significativo, uma vez que o comércio já representava uma das principais atividades econômicas da cidade:

O Sindicato dos Motoristas adere à campanha para funcionamento da Faculdade (CORREIO DA ARARAQUARENSE, 13 fev. 1957, p. 6).

Também a Associação Comercial se manifesta em prol da Faculdade de Filosofia (DIÁRIO DA REGIÃO, 15 fev. 1957, p. 1 e 5).

Segundo a imprensa, tal movimento teve sua ação e/ou influência repercutida nas esferas estaduais, como se constata nas notícias a seguir:

Repercute nos Campos Elíseos o movimento em prol da Faculdade de Filosofia (A TRIBUNA, 12 fev. 1957, p. 6).

Interesse do governador pela Faculdade de Filosofia de Rio Preto (A NOTÍCIA, 12 fev. 1957, p. 6).

Ao obter a autorização para seu funcionamento por meio do Decreto Federal 41.061 de 27 de fevereiro de 1957, a FFCL de Rio Preto passou a se distinguir das demais FFCLs justamente por ter sido fundada como uma faculdade municipal ${ }^{5}$ e não estadual; diferenciando-se assim das FFCLs de Araraquara, Assis, Marília, Presidente Prudente e Rio Claro, criadas como Institutos Isolados do Ensino Superior do Estado de São Paulo.

A obtenção da autorização de funcionamento da FAFI na Assembleia Legislativa Estadual foi acompanhada pelas páginas dos jornais, as quais noticiaram a satisfação da sociedade rio-pretense ante tal falto:

Uma vitória que veio encher de júbilo a comunidade riopretense (DIÁRIO DA REGIÃO, 17 fev. 1957, p. 1).

Aprovada pela Assembléia Legislativa a criação da Faculdade de Filosofia de Rio Preto (A NOTÍCIA, 20 fev. 1957, p. 1).

Dentre as notícias publicadas acerca da autorização e do reconhecimento da FFCL de São José do Rio Preto, duas foram as manchetes de seus respectivos jornais, o que denota a importância que tais fatos assumiram para a sociedade local:

Sancionada ontem a lei para o funcionamento da Faculdade de Filosofia (DIÁRIO DA REGIÃO, 28 fev. 1957, p. 1). 
Jânio agradece a Juscelino o reconhecimento da Faculdade de Filosofia de São José do Rio Preto (A TRIBUNA, 10 mar. 1957, p. 1).

Segundo artigo publicado na imprensa rio-pretense, a criação de uma FFCL em Rio Preto não foi fruto de interesses políticos, mas sim da mobilização da sociedade civil local: "A Faculdade de Filosofia de Rio Preto não foi criada por demagogia ou conveniências políticas" (CORREIO DA ARARAQUARENSE, 06 abr. 19576). Entretanto, de acordo com Oliveira (1989, p. 157), participaram do grupo rio-pretense que se empenhou pela criação de uma faculdade, "políticos populistas, autoridades administrativas, profissionais liberais e professores do Instituto de Educação Monsenhor Gonçalves - este considerado o "centro intelectual" da cidade, na época pré-filosofia". Já Vaidergorn (1995, p. 155-156 grifos do autor) defende que as "FFCL-IIES que terminaram sendo instaladas contaram, entre outros fatores, com um poderoso componente de apadrinhamento político, ao lado do "sistema meio empírico" do governador Jânio Quadros de fazer as coisas".

A despeito dos objetivos reais ou proclamados dos políticos, de setores da sociedade e da elite rio-pretense para a criação da FAFI, apenas um título de artigo jornalístico apresentou claramente uma das expectativas com relação à faculdade recémcriada: "Com a instalação da Universidade Municipal é lícito esperar para Rio Preto mais uma grande fase de progresso e de riqueza" (A NOTÍCIA, 07 abr. 1957).

Uma vez obtida a autorização para o funcionamento da FAFI, repercutiram nos jornais a atuação de seu diretor - Raphael Grisi, como também o planejamento e as ações para o início efetivo das atividades da faculdade. Dessa forma, os títulos das notícias sobre a FFCL passaram a se referir ao curso preparatório para o vestibular, ao início do ano letivo e à lista de candidatos aprovados no vestibular:

Funcionará um cursinho intensivo para vestibulares na Faculdade de Filosofia (A TRIBUNA, 03 mar. 1957, p. 5).

Marcadas as datas para os exames vestibulares da Faculdade (CORREIO DA ARARAQUARENSE, 13 mar. 1957, p. 6).

Marcado para $1^{\circ}$ de abril o início do ano letivo da Faculdade de Filosofia (A TRIBUNA, 13 mar. 1957, p. 1 e 5).

Encontra-se na cidade diretor da Faculdade de Filosofia (A NOTÍCIA, 27 mar. 1957, p. 1).

80 candidatos aos exames vestibulares da Faculdade (A NOTÍCIA, 30 mar. 1957, p. 1).

Os primeiros resultados dos exames vestibulares da Faculdade de Filosofia: entre os trinta candidatos inscritos 16 foram aprovados na secção de Pedagogia (A TRIBUNA, 08 abr. 1957).

Doado pelo Governador do Estado o terreno para a cidade universitária municipal de Rio Preto (A NOTÍCIA, 07 abr. 1957).

Além das notícias, com o efetivo funcionamento da FAFI iniciou-se também a publicação de editais e comunicados em que a faculdade dava ciência à população de suas atividades: "Prefeitura Municipal de São José do Rio Preto - Faculdade de Filosofia, Ciências e Letras - Concurso de Habilitação - Edital de Abertura de inscrições" (A NOTÍCIA, 19 mar. 1957, p. 6).

A FFCL de Rio Preto, primeira Faculdade de Filosofia, Ciências e Letras na região noroeste paulista, teve o início de suas atividades aguardado e celebrado pelos jornais locais como um fato histórico para a cidade, é o que evidenciam os títulos das notícias publicadas entre março e abril de 1957: 
A aula inaugural da Faculdade: diversas autoridades serão convidadas (A NOTÍCIA, 22 mar. 1957, p. 1).

A aula inaugural da Faculdade (CORREIO DA ARARAQUARENSE, 24 mar. 1957, p. 6).

Juscelino assistirá à aula inaugural da Faculdade de Filosofia de Rio Preto (A TRIBUNA, 26 mar. 1957, p. 1).

Instalação da Faculdade de Filosofia, Ciências e Letras de São José do Rio Preto - a aula inaugural será proferida em solenidade pública, no próximo dia $10,4^{\mathrm{a}}$ feira, às $20 \mathrm{~h}$ no Cine-Teatro Rio Branco - o que se espera da nova instituição (A TRIBUNA, 08 abr. 1957).

Brilhante solenidade marcou oficialmente a instalação da Faculdade de Filosofia (DIÁRIO DA REGIÃO, 11 abr. 1957).

O funcionamento da Faculdade de Filosofia - telegramas do Presidente da República e ofício do Prefeito de Votuporanga (DIÁRIO DA REGIÃO, 07 abr. 1957).

A referência a uma possível vinda do presidente da República e depois ao recebimento de seu telegrama, indicada nas páginas de um jornal, demonstra a relevância assumida pela cidade em razão do funcionamento de uma FFCL no interior paulista. Houve também a publicação de um artigo, sem autoria identificada, que expressou um ponto de vista a respeito da importância do início das atividades da FAFI como um grande acontecimento para a história rio-pretense: " 8 de abril - um grande dia para a história de Rio Preto" (A NOTÍCIA, 26 mar. 1957, p. 1).

Enquanto a faculdade municipal iniciava seu funcionamento, começaram as tentativas de sua incorporação aos Institutos Isolados de Ensino Superior do Estado de São Paulo. Primeiramente, com o Projeto de Lei n. 602/56, que criava a FFCL-IIES de São José do Rio Preto, todavia o governador vetou o projeto em 4 de abril de 1957, após consulta ao Conselho Estadual de Ensino Superior (CEES). Contudo, em virtude da mobilização de políticos locais, tal veto foi derrubado pelo deputado Aloysio Nunes Ferreira em plenário da Assembleia Legislativa, que promulgou a Lei n. 3884/57.

Assim sendo, os títulos das notícias jornalísticas repercutiram como ocorreu essa mobilização com vistas à estadualização da FFCL, indicando como principal argumento para tal processo o fato de a prefeitura municipal não dispor de verbas suficientes para manter o pleno funcionamento da faculdade:

A nossa Faculdade de Filosofia precisa ser encampada pelo Estado (A NOTÍCIA, 14 mar. 1957, p. 1).

Finalmente a disposição de nossa Faculdade de Filosofia - 3 milhões de cruzeiros (A NOTÍCIA, 27 set. 1957, p. 1).

Explicações do Prefeito Municipal sobre a verba para a Faculdade de Filosofia (DIÁRIO DA REGIÃO, 09 nov. 1957, p. 6).

Não foi aprovada a verba para a Faculdade de Filosofia de nossa cidade (A TRIBUNA, 20 nov. 1957, p. 1).

Como a incorporação era recorrentemente adiada pelo governo estadual e já havendo uma lei que criava uma Faculdade de Filosofia, Ciências e Letras do Estado de São Paulo, em 1958 realizou-se uma campanha para a efetiva estadualização da faculdade municipal:

Alunos liderados pelo CAF e professores congregados em seu órgão máximo fizeram a campanha entre a população e as instâncias superiores. 
A congregação elaborou documento base com exposição dos motivos que indicavam que a pretendida estadualização traria vantagens ao Estado e ao ensino superior. (OLIVEIRA, 1989, p. 58).

Essa campanha contou com a intensa atuação dos professores e alunos da FAFI e do prefeito Alberto Andaló, os quais organizaram uma comitiva para uma audiência com o governador Jânio Quadros a respeito da estadualização da faculdade, sendo divulgada nas notícias publicadas pela imprensa local:

A campanha para a estadualização da nossa Faculdade de Filosofia (CORREIO DA ARARAQUARENSE, 11 mai. 1958, p. 4).

Possível a necessária e reclamada estadualização de nossa Faculdade de Filosofia. (DIÁRIO DA REGIÃO, 11 mai. 1958, p. 1).

Professores e alunos da Faculdade de Filosofia avistar-se-ão amanhã com o governador (CORREIO DA ARARAQUARENSE, 13 mai. 1958, p. 1).

Encampação da Faculdade de Filosofia: Hoje a audiência com o governador do Estado. (DIÁRIO DA REGIÃO, 14 mai. 1958, p. 1).

Uma reportagem, sem autoria identificada, repercutiu também a mobilização em torno da campanha para a estadualização da FFCL: "Rio Preto e região pedem ao governo do Estado a oficialização da Faculdade de Filosofia" (A NOTÍCIA, 13 mai. 1958, p. 1 e 6). Faz-se necessário destacar a escassa publicação de reportagens sobre a FAFI, visto que os jornais rio-pretenses limitaram-se predominantemente a noticiar os fatos que envolviam a faculdade, porém não enfocaram de modo mais abrangente os assuntos relativos à FFCL com a produção de reportagens, a despeito da alegada importância histórica dessa instituição para a cidade e a região.

Dessa forma, a FFCL de São José do Rio Preto foi estadualizada pela Lei n. 5.177, de 13 de janeiro de 1959, constituindo-se uma das primeiras FFCLs do interior paulista a ser mantida pelo governo estadual, uma vez que as FFCLs de Assis e Marília, criadas em 1957, têm seu funcionamento autorizado em 16 de janeiro de 1959. A imprensa local acompanhou o processo de estadualização da FAFI, fato esse indicado nas seguintes notícias:

Autorizou o governador a criação da Faculdade de Filosofia Estadual em Rio Preto (CORREIO DA ARARAQUARENSE, 15 mai. 1958, p. 1).

Aprovada a Doação do Patrimônio da Faculdade de Filosofia local ao Governo do Estado (A TRIBUNA, 25 jun. 1958, p. 1).

Dependendo da conclusão das obras do prédio a estadualização de nossa Faculdade de Filosofia (A TRIBUNA, 22 jan. 1959, p. 1).

Após o início do funcionamento das atividades da FFCL ocorreu um progressivo distanciamento entre a faculdade e a sociedade local, que refletiu uma ruptura entre o modelo de faculdade adotado pela FAFI e o modelo almejado pela elite, por políticos e setores da sociedade rio-pretense - envolvidos com a criação da faculdade e desconsiderados quando da formação de seus quadros docentes e administrativos. Tal distanciamento pode ser observado no gráfico a seguir sobre o número de matérias jornalísticas acerca da FFCL na imprensa rio-pretense: 


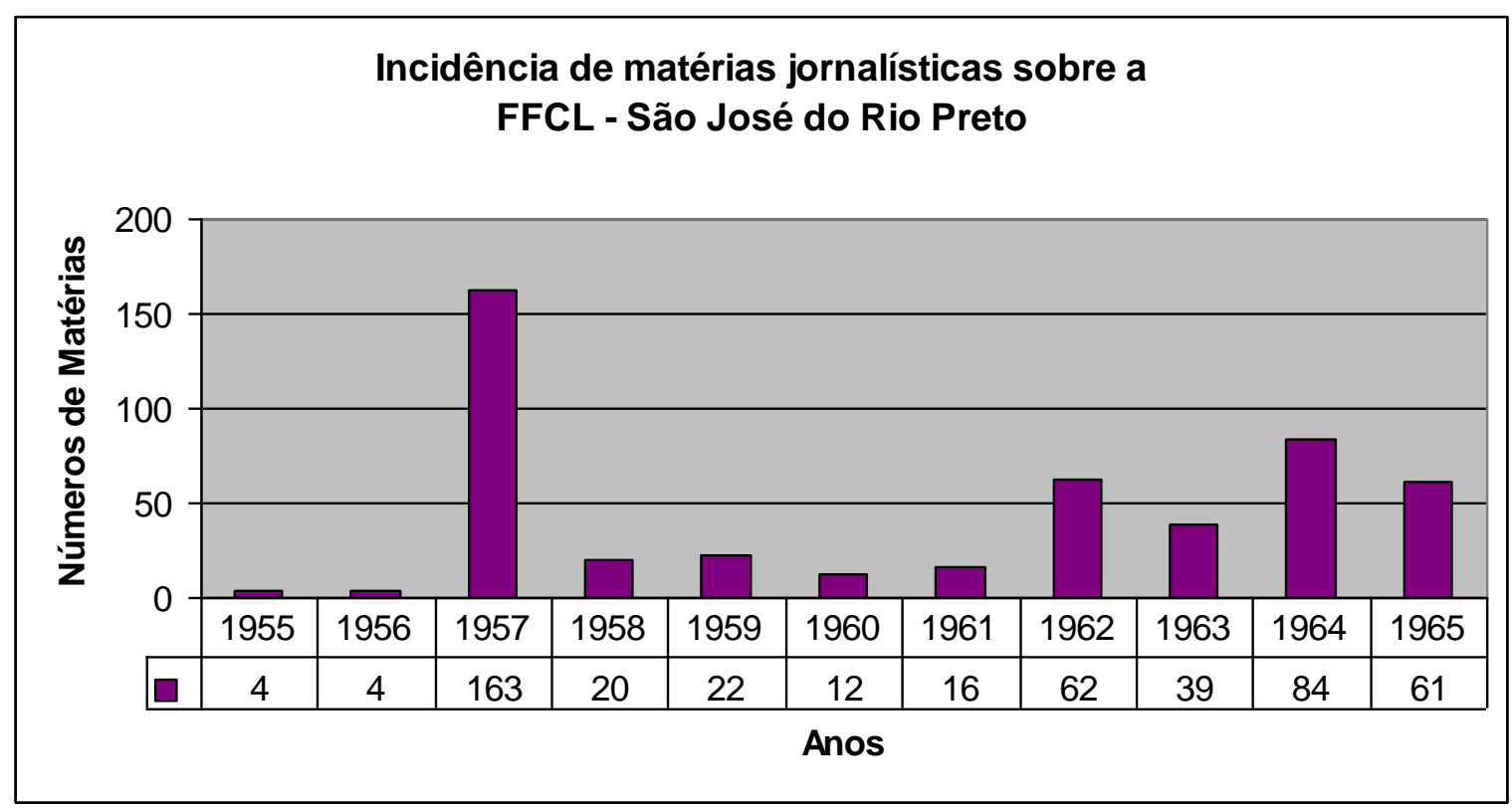

Fonte: Levantamento de publicações acerca da FFCL (1955-1965) na Hemeroteca Municipal Professor Dário de Jesus. Preservação de Fontes da Educação Brasileira: a estruturação do arquivo histórico da FAFI/São José do Rio Preto, 2003.

O gráfico anterior indica que o ápice da presença da FAFI na imprensa rio-pretense ocorreu em 1957, ano da autorização de seu funcionamento e momento em que foram publicadas 163 matérias jornalísticas a respeito da FFCL, imediatamente no ano seguinte houve um decréscimo de $87,74 \%$ no número de matérias sobre a faculdade em relação ao ano anterior. É evidente que, passado o momento inicial de inauguração e princípio de funcionamento da FAFI, aconteceria uma diminuição das atenções dirigidas à faculdade, todavia houve uma queda vertiginosa na quantidade de matérias jornalísticas a respeito da faculdade já em 1958, acentuando-se nos anos de 1960 e 1961. Novos picos da presença da FFCL sucederam somente nos anos de 1962, 1964 e 1965, embora em uma proporção significativamente inferior às ocorrências de 1957, sendo que esses dois últimos anos envolveram o conturbado período da ditadura militar.

A despeito desse progressivo distanciamento, a importância de uma Faculdade de Filosofia, Ciências e Letras para São José do Rio Preto e região foi mencionada nos jornais:

Sob orientação nova e segura: Faculdade de Filosofia lidera o grupo de Faculdades do Interior (A NOTÍCIA, 03 mai. 1962, p. 8).

Faculdade de Filosofia de Rio Preto: Mais destacado centro destacado centro de todo o oeste do Estado - prefeitura desenvolve esforços para a transformação do prédio (A NOTíCIA, 05 ago. 1962, p. 2).

Focalizando a função regional das Faculdades de Filosofia (A NOTÍCIA, 20 out. 1962 , p. 8 ).

Com relação à importância exercida pela FAFI, houve, ainda, a publicação de um trabalho escrito pela professora do curso de Pedagogia - Sarah Rottenberg - em forma de artigo jornalístico, além de duas reportagens, sendo que apenas uma delas teve seu autor identificado: 
Da importância da Faculdade de Filosofia de São José do Rio Preto na região (ROTTENBERG, S. A NOTÍCIA, 25 dez. 1960, p. 15).

Há apenas quatro anos de sua instalação, a Faculdade de filosofia é um autêntico centro de ensino e pesquisa (A NOTÍCIA, 01 mar. 1961, p. 8). Dinamizadas as atividades na Faculdade de Filosofia local (VALLE, R. do. DIÁRIO DA REGIÃO, 03 fev. 1962, p. 3).

$\mathrm{O}$ fato de algumas notícias e reportagens, bem como um artigo, reiterarem o valor e o prestígio alcançados pela faculdade pode também ser um indício de que setores da sociedade local começavam a contestar a FAFI tal como ela se constituiu - alheia aos seus interesses.

Além disso, aludia-se à importância da FFCL, nos jornais locais, quando acontecia alguma situação que envolvia o prestígio da faculdade para além dos limites da vida local, como indicam as notícias a seguir:

Governador visitará a Faculdade de Filosofia (A NOTÍCIA, 15 abr. 1962, p. 15).

Professor norte-americano visitou a Faculdade de Filosofia (A NOTÍCIA, 06 nov. 1962, p. 1-2).

Em virtude desse progressivo distanciamento entre a FFCL e a sociedade riopretense, a imprensa passou a noticiar, em geral, eventos acadêmicos e congressos, paulatinamente o entusiasmo que envolvia as referências à faculdade nas páginas dos jornais arrefeceu:

Faculdade de Filosofia, Ciências e Letras: virá a Rio Preto, como professor visitante, o doutor Paulo Sawaya, catedrático de Filosofia Geral e Animal na USP (CORREIO DA ARARAQUARENSE, 05 nov. 1957, p. 6).

Hoje, na Faculdade de Filosofia, 'A poesia e a pesquisa moderna' o tema a ser desenvolvido (A NOTÍCIA, 06 ago. 1960, p. 2).

Será iniciado dia 18 na Faculdade de Filosofia local importante curso de extensão universitária (A NOTÍCIA, 04 set. 1962, p. 5).

II Curso de Extensão Universitária da Faculdade de Filosofia subordinado ao título de "Métodos e materiais audiovisuais na educação". (DIÁRIO DA REGIÃO, 20 out. 1962, p. 2).

Inicia-se amanhã a I Semana Universitária (A NOTÍCIA, 17 jul. 1964, p. $8)$.

Professores da FAFI ministrarão simpósio (A NOTÍCIA, 10 set. 1965, p. $5)$.

Em raras situações, a imprensa noticiava outras atividades relacionadas à vida acadêmica, tais como reconhecimento de cursos, formaturas e defesa de tese.

Após quatro anos de funcionamento a Faculdade de Filosofia, Ciências e Letras de Rio Preto vê colar grau sua primeira turma de formandos (A NOTÍCIA, 15 abr. 1961, p. 8).

Reconhecimento dos cursos da Faculdade de Filosofia (A NOTÍCIA, 12 nov. 1964, p. 12).

Oficializados diversos cursos da Faculdade de Filosofia (CORREIO DA ARARAQUARENSE, 27 dez. 1964, p. 10). 
Primeira tese de doutoramento da Faculdade de Filosofia (A NOTÍCIA, 09 mai. 1965, p. 1-2).

Com relação ao perfil do corpo discente da FFCL, alguns alunos provinham de São José do Rio Preto, enquanto a maioria procedia das cidades da região, fato previsível, visto que Rio Preto exercia a função de polo de atração de sua vasta região.

No que concerne ao movimento estudantil, ele se congregava, na FAFI, em torno dos seguintes grupos: o GRUTA (Grupo Universitário de Trabalhos Artísticos), o MCP (Movimento de Cultura Popular) e o CAF (Centro Acadêmico de Filosofia), sendo que os dois primeiros foram organizados por docentes e alunos, já o último constituía-se como um organismo exclusivamente estudantil.

Criado somente em 1961, sob a influência do professor Orestes Nigro do Departamento de Letras e de alunos da faculdade, o GRUTA desenvolvia estudos, debates e apresentações de diversas manifestações artísticas, além de fomentar a participação artística de professores, alunos e funcionários, num ambiente de ousadia e sensibilidade. Algumas das atividades do GRUTA foram noticiadas na imprensa local:

Semana de Estudos Brasileiros (A NOTÍCIA, 05 ago. 1962, p. 12). Agradecimentos do Grupo Universitário de Teatro Amador (A NOTÍ́CIA, 08 nov. 1962, p. 10).

Coro da Igreja Metodista e Grupo de Jograis do Gruta hoje na Faculdade de Filosofia (DIÁRIO DA REGIÃO, 15 dez. 1962, p. 8).

Em virtude da atuação do GRUTA, a companhia Teatro de Arena passou a encenar suas peças na cidade, sendo que os atores Gianfrancesco Guarnieri e Juca de Oliveira promoveram conferências e debates com os alunos, o que propiciou o início de uma intensa programação cultural. Em depoimento concedido à Amorim (2009), Orestes Nigro rememorou algumas das atividades desenvolvidas pelo GRUTA:

Levamos para se apresentar na Faculdade a Inezita Barroso que sabe tudo de folclore, a Maria Lívia São Marcos que era a maior violinista do Brasil; levamos o Gianfrancesco Guarnieri para fazer uma conferência sobre teatro, ela acabou se tornando um grande amigo, tenho até algumas fotos dele jovenzinho, o Juca de Oliveira veio com ele e também ficou meu amigo. Tempos depois resolvemos fazer a Semana de Estudos Brasileiros, no mês de agosto e convidei a companhia de teatro do Fernando Torres, marido da Fernanda Montenegro para se apresentar em Rio Preto. (NIGRO apud AMORIM, 2009, p. 82-83).

A arte era uma forma escolhida pelo GRUTA para se refletir a respeito da realidade brasileira, ou seja, a cultura não era considerada como isolada da vida social. Sob tal perspectiva, ocorreu a atuação do GRUTA juntamente ao MCP no trabalho de alfabetização de adultos, em alguns bairros e fazendas próximas a Rio Preto, porém não houve referências diretas à atuação do MCP por parte imprensa. As atividades culturais promovidas na faculdade, seja pelo GRUTA, seja pela iniciativa de professores e demais alunos, consistiam em outro aspecto relativo à FAFI que continuou a ser foco das atenções dos jornais locais, como demonstram as seguintes notícias:

Inaugura-se hoje na Faculdade de Filosofia exposição comemorativa do $1^{\circ}$ centenário da morte de Alexandre Von Humboldt (A NOTÍCIA, 24 nov. 1959 , p. 8). 
Semana de Estudos Brasileiros: Pintor Silva vai expor hoje na Faculdade de Filosofia (A NOTÍCIA, 01 ago. 1962, p. 1).

Recital de Piano na Faculdade, amanhã (DIÁRIO DA REGIÃO, 05 nov. 1963, p. 1).

Ontem: Exibição de filme na FAFI (A NOTÍCIA, 05 dez. 1963, p. 1).

Exposição de pintura na Filosofia (A NOTÍCIA, 06 dez. 1963, p. 1).

Cadeira de Literatura Alemã e Instituto Goethe ofereceram noite de cultura na FAFI local (A NOTÍCIA, 16 set. 1964, p. 8).

Quanto ao CAF, ele foi criado em 1957 e dirigido pela vanguarda estudantil da faculdade, eleita em pleitos no quais concorriam também candidatos conservadores (autointitulados centro, brancos ou nacionalistas):

$\mathrm{O}$ CAF liderou os movimentos de resistência às crises administrativas e políticas que a "Filosofia" enfrentou ao longo de seus quase oito anos. Participou também ativamente de campanhas nacionais como a Defesa da Escola Pública, Posse de Jango, Campanha das Reformas de Base, Campanha da Reforma Universitária etc. (OLIVEIRA, 1989, p. 126).

Nesse sentido, o CAF assumiu a liderança do movimento estudantil na FAFI e participou, ativamente, das lutas e dos debates de temas acerca da educação, da universidade e da vida nacional, como indicam os títulos das notícias a seguir:

Pugnam os alunos pela consolidação da Faculdade de Filosofia (CORREIO DA ARARAQUARENSE, 09 nov. 1957, p. 2).

Estudantes da FFCL hipotecaram solidariedade ao candidato Maurício Goulart (DIÁRIO DA REGIÃO, 02 jul. 1959, p. 1 e 8).

Greve dos universitários riopretenses em solidariedade ao movimento dos estudantes da escola de engenharia do Mackenzie (A NOTÍCIA, 20 abr. 1960, p. 8).

Greve de apoio aos universitários do Mackenzie (A NOTÍCIA, 02 jun. 1962, p. 8).

Lei Suplicy: DAF promove debates (A NOTÍCIA, 29 ago. 1965, p. 8).

No que se refere ao corpo docente da FFCL, este foi selecionado quando a faculdade ainda era municipal. Segundo Vaidergorn (1995, p. 166), o diretor Raphael Grisi "escolheu os melhores estudantes da USP, os "rebeldes" que pretenderão transplantar a mentalidade moderna da USP para o interior", além de alguns professores estrangeiros e de uns poucos professores do Instituto de Educação Monsenhor Gonçalves. Newton Ramos de Oliveira (1989) cita um depoimento de Orestes Nigro (integrante do primeiro corpo docente da FFCL), concedido à sua pesquisa de mestrado, em que este classificou os professores da FAFI em três tipos, a saber, os "rebeldes" da USP, os indicados do Instituto de Educação e os professores estrangeiros:

Ao lado dos "rebeldes da USP", que por ordem de maior 'periculosidade' cito aqui - Rodolpho Azzi, Wilson Cantoni, Norman Maurice Potter, José Aloysio Reis de Andrade, Orestes Nigro e Bruna Anna Denti - chegavam também João Jorge Cunha da Universidade Nacional do Rio de Janeiro, logo alinhado com os "rebeldes"; Luis Dino Vizzoto, Alberto Barbosa Pinto Dias, trazidos por indicação do Prof. Celso Abbade Mourão, que há dois anos era efetivo de Ciências e Biologia no I. E. Monsenhor Gonçalves; - e mais os estrangeiros Erich Arnold Von Buggenhagen, 
Edoardo Querin e o lusitano Antonio Pinto de Carvalho [...]. (NIGRO apud OLIVEIRA, 1989, p. 57).

De acordo com Attab (1973), tal corpo docente não correspondeu às expectativas que a população possuía acerca do perfil de professores do ensino superior. "A maioria, além de ser agnóstica, era jovem, descuidada com a aparência e muito agressiva" (ATTAB, 1973, p. 20). Segundo a autora, se essa era a imagem que algumas pessoas tinham a respeito do grupo de professores renovadores, o mesmo não ocorria com relação aos professores do curso de História Natural, os quais se integraram rapidamente aos grupos da elite local: "Muito do que anteriormente já foi dito não se aplica a esses professores e todos eles, com exceção de um, foram muito bem recebidos por todas as áreas do Município." (ATTAB, 1973, p. 24).

Nesse sentido, a política de contratação empreendida pelo diretor da FAFI já começava a provocar certa oposição e algumas polêmicas por parte de setores da sociedade rio-pretense, uma vez que os professores do referido Instituto de Educação, considerado o centro intelectual da cidade, almejavam ocupar os cargos docentes da recém-criada faculdade. Tal aspiração dos professores do Instituto de Educação Monsenhor Gonçalves repercutiu na imprensa local, como evidencia a seguinte notícia: "Comitê pró professor Daud na Faculdade de Filosofia, Ciências e Letras" (DIÁRIO DA REGIÃO, 03 jul. 1959, p. 1). Adiciona-se a essa questão o fato de alguns círculos rio-pretenses discordarem do comportamento e da mentalidade dos professores vindos de outras cidades, denominados professores renovadores: "Para esse grupo do poder local, traduzindo um sentimento comum a outras FFCL-IIES a Faculdade não correspondia à sua aspiração de classe." (VAIDERGORN, 1995, p. 166-167 - grifos do autor).

Diante das características do corpo docente inicial da FFCL e dos depoimentos coletados em sua dissertação, Oliveira (1989) dividiu esse grupo inicial de professores em dois blocos. O grupo majoritário era constituído pela maioria dos docentes dos cursos de Pedagogia e de Letras (Anglo-Germânicas e Neolatinas), já o grupo minoritário detinha o maior número dos professores do curso de História Natural. Tal relação de forças mantevese constante até o ano de 1964.

Nesse sentido, um índice do referido alinhamento entre os professores do curso de História Natural e setores da sociedade rio-pretense consiste no fato de que esse curso constituiu o único cujas atividades eram amplamente divulgadas pela imprensa com a publicação de diversas notícias:

Centro de Estudos de História Natural: posse da nova diretoria - sessão solene às 20 horas de sexta-feira na Faculdade de Filosofia (A NOTÍCIA, 16 mai. 1962 , p. 8 ).

Eminente paleontólogo da Universidade de São Paulo (A NOTÍCIA, 05 jul. 1962, p. 8).

Verbas para as cadeiras do Curso de História Natural (A NOTÍCIA, 17 jul. 1962, p. 8)

Convidado catedrático de Botânica da nossa Faculdade de Filosofia (A NOTÍCIA, 19 set. 1962 , p. 1).

Cadeira de Biologia da Faculdade de Filosofia comunica a realização de exame sobre o Curso de extensão universitária para 13 de outubro. (A NOTÍCIA, 26 set. 1962, p. 8).

"Evolução da vida" dia 30: Conferência na Faculdade (DIÁRIO DA REGIÃO, 24 nov. 1962, p. 8).

Iniciado na Faculdade o curso de Gemologia (CORREIO DA ARARAQUARENSE, 11 set. 1963, p. 8). 
Há quase um vácuo com relação a matérias jornalísticas sobre os cursos de Pedagogia e Letras da FAFI, justamente os cursos cuja maioria dos docentes fora considerada "rebelde" ou de mentalidade muito renovadora para uma cidade provinciana. Eis alguns dos títulos de notícias relacionadas a esses cursos:

Dr. Jorge de Sena visita nossa Faculdade de Filosofia (CORREIO DA ARARAQUARENSE, 19 abr. 1963, p. 1).

Palestras sobre psicologia infantil na Faculdade de Filosofia (DIÁRIO DA REGIÃO, 01 ago. 1963, p. 12).

Ciclo de conferências sobre modernismo português começa amanhã na FAFI (A NOTÍCIA, 04 out. 1964, p. 11).

Entre os anos de 1955 e 1965, foram publicados 33 títulos de matérias jornalísticas referentes ao curso de História Natural, ao passo que somadas todas as matérias sobre os cursos de Pedagogia e Letras nesse período elas totalizaram 19 títulos. O cotejo desses dados indica que cerca de $57 \%$ das matérias jornalísticas relacionadas a cursos e/ou departamentos da FFCL referem-se ao curso de História Natural. Não é uma coincidência o fato de que somente esse curso selecionou professores do referido Instituto de Educação Monsenhor Gonçalves, constituindo um corpo docente que, em sua maioria, estava alinhado à imagem, à mentalidade e aos valores dos grupos da elite local. Por conseguinte, as atividades desenvolvidas nesse curso passaram a ser amplamente divulgadas nas páginas dos jornais, sendo publicadas até reportagens sobre as pesquisas desenvolvidas pelo departamento de História Natural: "O solo e o subsolo de Rio Preto ( $1^{\text {a }}$ de uma série de reportagens): Atividades da Cadeira de Mineralogia e Petrologia da Faculdade de Filosofia" (A NOTÍCIA, 17 dez. 1963, p. 7).

Aliás, a combatividade de diversos professores da FAFI pode ser notada diante do fato de eles não se furtarem a participar dos debates de seu tempo, juntamente com os alunos da faculdade, o que já se poderia supor em virtude do caráter contestador da maioria de seus professores. Tal fato pode ser observado nas seguintes notícias:

Debates na Faculdade de Filosofia sobre diversos problemas ligados à vida nacional (A NOTÍCIA, 13 out. 1960, p. 2).

Prévia na Faculdade de Filosofia apontou vitória de José Bonifácio (A NOTÍCIA, 20 set. 1962, p. 1-2).

Hoje às 14 horas: Professores primários e secundários reúnem-se na Faculdade de Filosofia (A NOTÍCIA, 18 out. 1963, p. 8).

Debate sobre Universidade na FAFI (A NOTÍCIA, 15 out. 1965, p. 8).

A atualidade política e econômica do Brasil: conferência de Levy na FAFI (A NOTÍCIA, 19 nov. 1965, p. 1).

Portanto, fica evidente que a FFCL não satisfazia aos interesses da classe dominante local, que consistiam na formação de estudiosos tradicionais, profissionais destinados ao nível secundário de ensino e, sobretudo, adaptados ao sistema. Tais profissionais deveriam reproduzir ideias políticas, econômicas, sociais e culturais alinhadas aos seus interesses. Gradativa e cumulativamente formou-se um grupo de oposição à FAFI:

[...] que se fortaleceu quando o modelo "Filosofia" extrapolou o debate acadêmico interno e ousou invadir (em suas atividades de ensino e pesquisa) espaços locais/regionais/nacionais e, em especial, espaços sociais de classe, ao optar na centralização de seus interesses nas camadas 
populares e na classe trabalhadora da cidade e do campo. Mas essa oposição - mesmo forte ao extremo, agora - não teria derrotado a "Filosofia" se não tivesse havido a "centelha". Essa centelha foi o golpe de 1964 - muito bem aproveitado pelos interessados - que alterou, brusca e violentamente, os parâmetros da legalidade. (OLIVEIRA, 1989, p. 214 - grifos do autor).

Já Attab (1973) sustenta que a FAFI sofreu uma hostilidade latente da área municipal desde o momento de sua implantação. Além disso, a autora imputa as divergências entre os dois blocos de professores às diferenças de formação acadêmicopedagógica, às antipatias pessoais e à luta pelo poder interno.

Não obstante, a intensidade dessa oposição à FFCL só foi constatada a partir da violenta repressão exercida contra a comunidade acadêmica com o golpe de 1964 . Na primeira semana do golpe, professores e alunos da FAFI foram presos e perseguidos, enquanto as suas bibliotecas foram devassadas e muitos deles denunciados por seus pares. De acordo com Aliberti (2007, p. 38), "estima-se que tenham ocorrido mais de 200 prisões"7.

No dia 19 de maio de 1964, nove professores foram sumariamente demitidos pelo governador Ademar de Barros, com base em Ato Institucional, a repressão chegava à FAFI, o que foi noticiado pela imprensa local:

Situação da Faculdade de Filosofia (CORREIO DA ARARAQUARENSE, 03 abr. 1964, p. 8).

Novos regentes da cadeira de Língua e Literatura francesa da Faculdade (CORREIO DA ARARAQUARENSE, 07 jul. 1964, p. 8).

Visita à Faculdade de Filosofia: Imprensa e vereadores presentes (DIÁRIO DA REGIÃO, 01 set. 1964, p. 12).

Professores da Faculdade de Filosofia dispensados (CORREIO DA ARARAQUARENSE, 22 mai. 1964, p. 1).

Docentes da Faculdade de Filosofia dispensados (CORREIO DA ARARAQUARENSE, 11 jun. 1964, p. 1).

Faculdade de Filosofia: DAF com nova diretoria (A NOTÍCIA, 28 mar. 1965, p. 8).

DAF convida Lacerda (A NOTÍ́CIA, 06 jul. 1965, p. 1).

Diretório Acadêmico da FAFI decide revogar os estatutos (A NOTÍCIA, 17 ago. 1965, p. 8).

Conferências anti-comunistas nas faculdades e nos colégios (A NOTÍCIA, 26 ago. 1965, p. 8).

Consequentemente, para o cargo dos docentes demitidos, vítimas dos expurgos do regime militar, foram contratados professores secundários, profissionais liberais $\mathrm{e}$ autoridades administrativas locais, na busca por concretizar um modelo de faculdade adequada às aspirações da sociedade local.

Para impedir qualquer solução de continuidade ao modelo de ensino e pesquisa desenvolvido pela FFCL, em maio de 1964, o juiz de Direito José de Castro Duarte foi nomeado diretor da faculdade, segundo depoimentos esse juiz era conhecido como "carrasco da Ilha Grande" (AMORIM, 2009, p. 138). A nomeação do novo diretor da FAFI fez-se presente nas seguintes notícias: 
Expurgo e nomeação de novo diretor na Faculdade - assunto principal da reunião de ontem na Câmara (CORREIO DA ARARAQUARENSE, 08 abr. 1964, p. 8).

Diretor-interino da Faculdade de Filosofia (CORREIO DA ARARAQUARENSE, 21 abr. 1964, p. 1).

O Dr. Castro Duarte deverá ser o diretor da Faculdade (CORREIO DA ARARAQUARENSE, 29 abr. 1964, p. 1).

A nomeação de um novo diretor para FFCL obteve o apoio de vários setores da sociedade rio-pretense. A oposição latente à FAFI decidiu, enfim, manifestar-se, fato esse claramente perceptível nos títulos das notícias a seguir:

Câmara manifesta favorável à indicação do juiz Castro Duarte (CORREIO DA ARARAQUARENSE, 29 abr. 1964, p. 8).

Entidades de nossa terra em unânime solidariedade ao diretor da Faculdade de Filosofia (CORREIO DA ARARAQUARENSE, 04 dez. 1964, p. 8).

Entidades manifestam-se: manutenção do Dr. José de Castro Duarte na direção da Faculdade de Filosofia (DIÁRIO DA REGIÃO, 04 dez. 1964, p. 12).

Associação dos advogados solidária ao diretor da Faculdade de Filosofia (DIÁRIO DA REGIÃO, 11 dez. 1964, p. 8).

Inspetora Regional de Ensino também solidária com diretor da Faculdade de Filosofia (CORREIO DA ARARAQUARENSE, 12 dez. 1964, p. 1).

As mesmas entidades que se envolveram na luta pela criação de uma faculdade em São José do Rio Preto expressaram, então, seu descontentamento quanto às características adotadas pela FFCL ao apoiar a intervenção na faculdade. Aliás, há um artigo assinado por Daud Jorge Simão, criador do projeto de lei que deu origem à faculdade, em que o referido professor expressa sua discordância e seu descontentamento com a orientação adotada pela FFCL: "A pedidos: Protesto contra um comunicado do diretor da Faculdade de Filosofia local” (SIMÃO, D. J. CORREIO DA ARARAQUARENSE, 04 abr. 1964).

Com relação à situação do corpo docente após o golpe militar, ocorreu a emigração de vários professores para universidades do exterior. Os docentes que permaneceram no país sofreram o chamado "exílio branco": alguns foram abrigados por escolas superiores ou por escolas experimentais católicas de ensino médio, alguns foram processados.

Assim sendo, o golpe de 1964 encerrou a experiência universitária da FFCL de São José do Rio Preto, as características do modelo de universidade erigido na FAFI são, pois, suficientes para demonstrar que os interesses da faculdade e os do regime militar eram inconciliáveis, o que gerou o término dessa experiência.

\section{Considerações Finais}

$\mathrm{Na}$ área da História da Educação, progressivamente o jornal consolida-se como fonte de investigação histórica. Este trabalho partiu, pois, do entendimento de que os jornais constituem um espaço privilegiado para a difusão de concepções e padrões de comportamento de setores da sociedade, bem como para a manifestação dos problemas, propostas, soluções, opiniões e ideias de grupos vinculados à elite da sociedade. Nas páginas dos jornais, apresentam-se as expressões de um diálogo constituído entre diversas vozes sociais, situadas em determinado tempo histórico (CAMPOS, 2004). 
De acordo com Faria Filho (2002, p. 134), no Brasil e em outros lugares, o jornal foi considerado como "uma importante estratégia de construção de consensos, de propaganda política e religiosa, de produção de novas sensibilidades, maneiras e costumes. Sobretudo os jornais foram vistos como importante estratégia educativa".

Nesse sentido, a análise dos títulos das matérias publicadas nos jornais rio-pretenses entre 1955 e 1965 forneceu elementos indicativos dos valores e das preocupações das classes e dos grupos predominantes de São José do Rio Preto acerca da FAFI. Por conseguinte, os títulos das matérias indicaram, inicialmente, a repercussão do movimento em prol da criação da faculdade e, em seguida, de sua estadualização. Além disso, os jornais expressaram o antagonismo latente estabelecido entre a FFCL e a elite local, o qual só se manifestou de maneira efetiva e contundente a partir do golpe militar.

\section{Referências Bibliográficas}

ALIBERTI, L. (org.). IBILCE 50 anos: histórias e memória de sua gente. São José do Rio Preto-SP: THS Arantes Ed., 2007.

AMORIM, M. A. B. V. No interior... ditadura militar e ensino superior (FAFI/UNESP): Memórias sobre a intervenção na Faculdade de Filosofia, Ciências e Letras de São José do Rio Preto. Dissertação (Mestrado em História). Universidade de São Paulo, São Paulo, 2009.

ANUÁRIO Estatístico do Brasil. Instituto Brasileiro de Geografia e Estatística. Rio de Janeiro, [s. n.], 1950.

A NOTíCIA. São José do Rio Preto: [s. n.], 1955, 1956, 1957, 1958, 1959, 1960, 1961, 1962, 1963, 1964, 1965. Diário.

A TRIBUNA. São José do Rio Preto: [s. n.], 1955, 1956, 1957, 1958, 1959, 1960, 1961, 1962, 1963, 1964. Diário.

ATTAB, Z. A. A experiência da Reforma Universitária na Faculdade de Filosofia, Ciências e Letras de São José do Rio Preto (1959-1964). Tese (Doutorado em Educação). Faculdade de Filosofia, Ciências e Letras de São José do Rio Preto, São José do Rio Preto, 1973.

BASTOS, M. H. C. "Espelho no papel: a imprensa e a história da educação". In: ARAUJO, J. C. S.; GATTI JÚNIOR, D. (Orgs.). Novos temas em História da Educação Brasileira. Campinas-SP: Autores Associados; Uberlândia-MG: EDUFU, 2002.

BOLÇONE, O. J. (Org.). Conjuntura econômica de São José do Rio Preto. 25. ed. São José do Rio Preto-SP: Secretaria Municipal de Planejamento e Gestão Estratégica, 2010.

CAMPOS, R. D. A "princesa do sertão" na modernidade republicana: urbanidade e educação na Rio Preto dos anos 1920. São Paulo: Annablume; São José do Rio Preto-SP: Secretaria Municipal de Cultura, 2004. 
CORREIO DA ARARAQUARENSE. São José do Rio Preto: [s. n.], 1955, 1956, 1957, 1958, 1959, 1960, 1961, 1962, 1963, 1964. Diário.

CUNHA, L. A. A universidade crítica: o ensino superior na República Populista. 2. ed. Rio de Janeiro: F. Alves, 1989.

DIÁRIO DA REGIÃO. São José do Rio Preto: [s. n.], 1955, 1956, 1957, 1958, 1959, 1960, 1961, 1962, 1963, 1964. Diário.

FARIA FILHO, L. M. de. "O jornal e outras fontes para a História da Educação mineira do século XX: uma introdução. In: ARAUJO, J. C. S.; GATTI JÚNIOR, D. (Orgs.). Novos temas em História da Educação Brasileira. Campinas-SP: Autores Associados; Uberlândia-MG: EDUFU, 2002.

GOMES, L. Gente que ajudou a fazer Rio Preto uma grande cidade. São Paulo: Editora Gráfica São José, 1975.

OLIVEIRA, N. R. de. Sapere Aude: a Faculdade de Filosofia, Ciências e Letras de São José do Rio Preto no período de 1957-1964. (Dissertação de Mestrado). Centro de Educação e Ciências Humanas, Universidade Federal de São Carlos, São Carlos: 1989.

VAIDERGORN, J. As seis irmãs: as Faculdades de Filosofia, Ciências e Letras Institutos Isolados de Ensino Superior do Estado de São Paulo - 1957-1964; alguns subsídios interpretativos para o estudo do ensino superior do Estado de São Paulo. Tese (Doutorado em Educação) - Faculdade de Educação, Universidade Estadual de Campinas, Campinas, 1995.

\section{Notas:}

1 Docente do curso de Pedagogia da FAIMI e doutoranda do Programa de Pós-Graduação em Educação Escolar da UNESP - Araraquara.E-mail: marcelalsgs@ hotmail.com

2 Para maiores informações acerca do município de São José do Rio Preto, confira Bolçone (2010).

${ }^{3}$ Doravante denominada apenas FFCL ou FAFI (como era conhecida em seus primeiros anos).

${ }^{4}$ Esclareço que o levantamento das matérias publicadas no ano de 1965 cobriu somente o jornal A Notícia.

5 A Faculdade de Farmácia e Odontologia de Araraquara fora criada em 1923 também como uma faculdade municipal, cuja estadualização ocorreu apenas em 1955, porém não se trata de uma Faculdade de Filosofia, Ciências e Letras, o que permite ressaltar a peculiaridade da FFCL de São José do Rio Preto em relação às demais FFCLs do Estado de São Paulo.

${ }^{6}$ Em virtude da transferência da Hemeroteca Municipal Professor Dário de Jesus da Casa de Cultura para o Arquivo Público Municipal, o volume com os jornais do mês de abril de 1957 foi extraviado, o que impossibilitou a identificação da página e dos possíveis autores das matérias relativas a tal data. Saliento, contudo, que não há a identificação de autoria na maior parte das matérias, sejam elas notícias, artigos ou reportagens.

7 O processo político instaurado contra os professores e os alunos da FAFI conta com oito volumes, cerca de 3.600 páginas e sua cópia encontra-se na biblioteca da UNESP de São José do Rio Preto.

Recebido em: $\quad 01 / 02 / 11$

Aprovado em: $\quad 02 / 03 / 11$ 